\title{
Jostling with jargon
}

\author{
Alden H. Harken, MD, ${ }^{\mathrm{a}}$ David A. Wood, Jr, PhD, ${ }^{\mathrm{b}}$ Frank W. Sellke, MD \\ From ${ }^{\mathrm{a} U C S F}-E$ ast Bay, Oakland, Calif; ${ }^{\mathrm{b}}$ Alamo Colleges/San Antonio College, San Antonio, Tex; ${ }^{\mathrm{c}}$ Brown Uni- \\ versity, Providence, RI; and ${ }^{\mathrm{d}}$ University of Toronto, Toronto, Ontario, Canada. \\ Received for publication July 28, 2019; revisions received July 28, 2019; accepted for publication July 31, 2019; \\ available ahead of print Nov 6, 2019 \\ Address for reprints: Alden H. Harken, MD, 1565 Alamo Way, Alamo, CA 94507 (E-mail: Alden.harken68@ \\ gmail.com). \\ J Thorac Cardiovasc Surg 2020;159:1925-6 \\ 0022-5223/ $\$ 36.00$ \\ Copyright (C 2019 Published by Elsevier Inc. on behalf of The American Association for Thoracic Surgery \\ https://doi.org/10.1016/j.jtcvs.2019.07.152
}

We recommend that authors concentrate on communicating with their readers and avoid jargon. After suffering silently through marathons of National Institutes of Health study sections and reviewing innumerable journal manuscripts, we request that authors choose words that convey their meaning to their intended audience. Literary dazzle may hack it in Hollywood, but dazzle is not an effective method to communicate. We believe that it is incumbent on authors to explain the relevance, meaning, and purpose of their methods, results, and conclusions. Some of the knock-out/knock-in molecular systems are truly beautiful-but authors should tell us how and why. Some of the statistical second derivatives really do capture the essence of change that is changing. Please tell us why.

We are frustrated that science and clinical medicine have grown apart to the huge disadvantage of everyone. Surgeons like us are sometimes reluctant to converse with our basic science colleagues (we worry that they will think we are stupid), and our professorial progenitor pals may be reluctant to talk to us (they think we are arrogant). That's wrong.

What is the problem? A superb current study in a highly acclaimed medical journal recently addressed the diagnostic and prognostic performance of their multiple high sensitivity test combinations by using "a derivation validation design." We believe this statistical wizardry was developed solely to confirm that their permutational storm of test combinations was successful in validating their initial hypothesis.

Cardiothoracic surgeons pride ourselves in accomplishing the practical clinical application of basic biological and physiological principles. To successfully extend our activities into the molecular and immunological spheres we must encourage our basic investigator colleagues to explain the mechanisms buried in their methodologic decision making. If, when exploring murine atherogenesis they select to measure monocyte chemo attractant protein 1, vascular cell adhesion molecule 1 ,

\section{and Richard D. Weisel, MD}

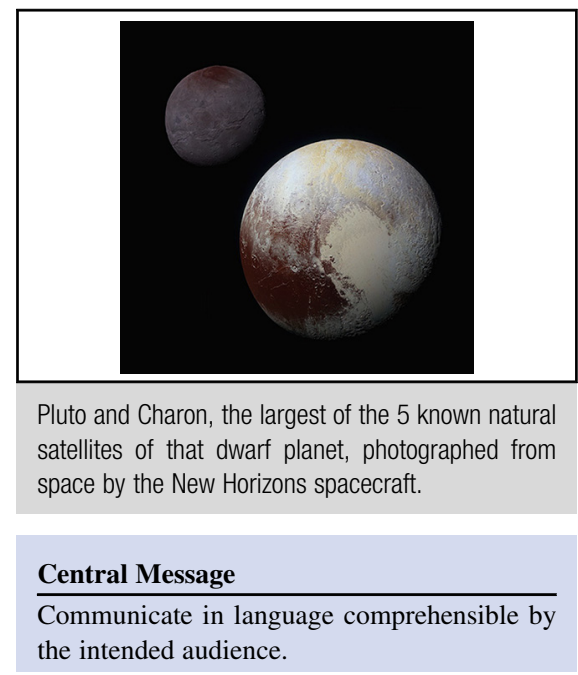

cluster of differentiation molecule 68, osteopontin, lectin-like oxidized low-density lipoprotein receptor 1 , hypoxia inducible factor 1 alpha, vascular endothelial growth factor, and tissue factor, they should tell us why. These markers were not selected at random; each molecular marker was presumably selected based on the investigator's concept of the mechanisms of arteriosclerosis. If the authors were to begin with an explanation of the mechanistic significance of each molecular building block, we could more capably participate in the interpretation of their results because we understand why the measurements were chosen. Credible clinical application is a guaranteed ticket to extramural funding. If step 1 is to communicate in words/concepts that convey meaning to the intended audience, step 2 is that we must rigorously delineate a focused clinical problem.

For example, consider the question of whether Pluto is a planet. We found an article entitled, "Does Pluto qualify as a planet?" The article begins with the definition of a planet from the International Astronomical Union. That sounded perfect. The International Astronomical Union cataloged the obligate criteria of a planet:

1. Is it in hydrostatic equilibrium?

2. Does it orbit the sun directly?

3. Is it dynamically able to clear its neighborhood?

We were daunted but we persisted. The authors noted Pluto's mass $\left(M_{p}\right)$, its $\Lambda$, its orbital $e$ and $i$, the composition $K_{\lambda}$, the HE, Pluto's resonance with Neptune as a KBO, and 
its general behavior as a TNO. After slogging through this methods section, our impulse was to question whether the authors really wanted to communicate with humans. But we did not give up. We decided, with some help, to create a glossary:

$M_{p}=$ mass of Pluto

$\Lambda=M_{p} / M_{\text {else }}=$ Pluto's mass relative to the remaining mass in its neighborhood $(\Lambda>1$ means it has cleared the neighborhood)

$e=$ Pluto's orbital eccentricity

$i=$ inclination of Pluto's orbit

$K_{\lambda}=$ Pluto's composition determined spectroscopically

$\mathrm{HE}=$ hydrostatic equilibrium; that is, the balance between gravity and hydrostatic pressure that determines an object's planetary shape

$\mathrm{KBO}=$ Kuiper belt objects; that is, objects beyond Neptune that are in orbital resonance with Neptune
$\mathrm{TNO}=$ trans-Neptunian objects; that is, all objects beyond Pluto (there is some geographic overlap with KBOs)

With this Rosetta Stone in hand, we puffed out our chests and read the article again. Our more educated conclusion: Pluto is not a planet.

We are not opposed to Czechoslovakian elders communicating the delights of their historical heritage in their lingua franca. Indeed, this may convey real beauty. But when basic and clinical scientists need to share important progress, we must mandate the kind of meaningful verbiage (or provide an explanatory glossary) that Francis Bacon, the pioneer in scientific inquiry, would have condoned.

\section{Conflict of Interest Statement}

Authors have nothing to disclose with regard to commercial support. 